\title{
TEAM ORGANISATION IN INTEGRATED ON-IINE COMPUTER PROJECTS
}

\author{
P. Hammersiey \\ Director of Computer Unit \\ Addenbrooke's Hospital \\ Hills Road, Cambridge CB2 2QQ, UK
}

\section{INTRODUCTION}

For most of the $1960^{\prime}$ s the development of computer systems for business purposes was centred on those systems which could be implemented in tems of a single batch program, or a 'suite' of such progname, processing sequential magnetic tape files with input from a card reader and output to one or more line printers. The programs usually were written in COBOL and most often were concemed with financial applications. The organisation of the computer department necessary to sustain this type of development has been described fully. An excellent summary appeared in coates (1974). In general, systems design, programming, and operations formed three distinct sections, each operating with a strictly hierarchical management structure.

The 1970's saw, however, a rapid expansion in the number and type of on-line systems. The need for computers to be used in promoting change in the decision making processes (Hardcastle, 1971), a requirement that information should be made available at least as quickly as it was before computer systems became commonplace, a requirement by users to control the input to and output from the systems which supported them, and a desire to explost the communication properties of on-line systems in order to eliminate errors, losses, and delays, all contributed their part to that expansion.

From the point of view of team onganisation there were many different types of online system. Many were concerned with small dedicated computers, undertaking some form of machine control, in which a single prognam coped with a limited set of processes. Others, particularly those using remote job entry teminals, displayed no different characteristics to the batch processing systems which they displaced. A third group had the characteristics of both of the two former; temixals were used for capturing data on-line during the day, with the data being written to file and accessed only in the evening. Then it was used as a serial file forming the input to a batch 'suite'. Among the remaining systems there was one special type, about which this paper is concerned, in which the computen system covered many different aspects of an onganisation and in which terminals attached to the system could input, access, or demand processing of any item of data supplied by any other teminal. Fon the purposes of this paper such a system is refemed to as an Integrated Information and Communication System (IICS).

Among those organisations which have seen the need fon an IICS have been hospitals. In England a number of hospitals have been able to establish an IICS through the direct support of the Department of Health and Social Security. One of them has been Addenbrooke's Hospital, Cambridge, where a team has been working on such a system since 
1969. Addenbrooke's is a long established teaching hospital which has recently moved into new buildings on the outskirts of the city. From the outset of planning the new buildings the IICS was seen as the only satisfactory method of overcoming the management and communication problems which were likely to arise when the buildings were commissioned (Hammersley, 1972).

A special characteristic of the development at Addenbrooke's was a restriction on the amount of finance available, leading to a relatively small team of systems and programming staff, fourteen in all. On the othex hand the task was complex. Users would have available approximately one hundred and fifty different possible operations, many of which would interact directly with others, these operations accessing a database with one hundred and ten recond types exhibiting approximately one hundred set relationships. It was felt that in order to complete the project in the time and with the resources available a new method of team organisation and planning strategy was needed. This paper describes the type of organisation chosen, the problems which it has thrown up, and the ways in which those problems were tackled. It attempts to assess whether or not the particular onganisation chosen has achieved the results which were expected of it.

\section{THE REASONS FOR CHOOSING A NEW STRUCTURE}

Early in the life of the project certain characteristics of an IICs were observed which indicated a different approach from that adopted previously. These were:

1. An on-line transaction between a user and the computer consisted of a set of inputs and responses, each covering a few items of information. Therefore the whole development had to be seen as a chain of equivalent tasks and not as a hierarchy of different ones.

2. Because much of the processing organisation was carried out by software packages the amount of code generated for each user operation was relatively small. This is shown clearly in the diagram of store utilisation given in Fig. 1. In the Xerox TP package, used to implement the system at Addenbrooke's, it was assumed that the user provided code would be written in COBOL. These two criteria indicated that the programming operation would occupy a smaller place relatively than had been the case before.

3. The success of an on-line system depended on the computer being able to respond to prompts in a time acceptable to the user. This required the systems designer to be fully aware of all aspects of the techniques used by the software packages to control the on-line operation.

4. The possible interaction of any one part of the total system with any other meant that any one user operation could generate effects elsewhere in the system. Hence each designer had to be fully aware of the operation of the total system and not the one application on which he was working. 


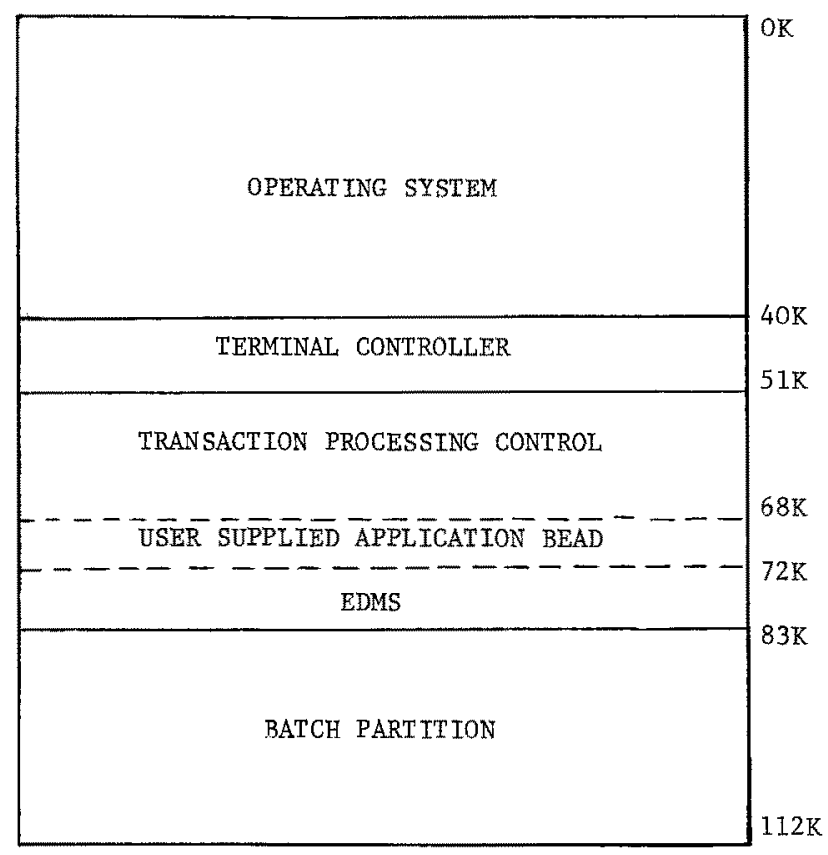

Fig. 1 Layout of core storage showing relative occupancy of user supplied program.

5. The involvement of users who had not themselves taken any part in the decision to proceed with a computer system, who were suspicious, and who were "naive" in the sense that they were unaware of the potential of computer systems, yet who would be operating the terminals on their own behalf, led to a situation where systems specifications would be changing continuously, right up to the time of implementation. This meant that there was a need for the systems designer to be aware of the total implications of an application so that changes could be effected quickly and painlessiy.

6. A total IICS was too large for any one individual to be able to see the scope for improvements and extensions. Each individual had to be in a position to feed new ideas into the development.

Against these requirements had to be set also the question of motivation, the element necessary to produce a complex system with the minimum of effort. Many programming departments have regarded programmers as coding clerks and have suffered from the consequences of a feeling by staff that they are not involved. It was essential to ensure that this situation did not arise.

The twin considerations of the nature of an on-line system, with its emphasis on the need for effective communication, and the need for considerable motivation for staff 
led to the conclusion that staff should be assigned not to a systems team nor to a programming team but to an applications team. Each member of the project would be responsible for the implementation of one application from preliminary study to final cutover.

\section{THE INITIAL TEAM STRUCTURE}

The provision of patient care in an English hospital was seen as falling into two clear divisions, care for those patients who could be treated in a short space of time, say half-an-hour, on during a sequence of short visits, and those who needed to be treated over a period of a few days whilst under constant observation in the hospital. The formen were referred to as outpatients and the latter as inpatients. The transactions to be provided also fell into two groups, those serving outpatient areas and those serving inpatient areas. It became apparent that a division of available staff into two teams was necessary. This division was imposed also by the geography of the hospital. The outpatient and inpatient areas were four hundred metres apart and the offices available to the computer staffs were separated by the same distance. Within each team's responsibility the nature of the transactions to be provided could be divided into four groups of applications, each group of which could be implemented as a complete entity, although because of interactions some groups would need to be introduced before others. Within each team one systems analyst was allocated to each of the four groups of applications.

The requirement for speedy implementation implied a requirement for as rigid a system of project control as could be achieved consistent with providing motivation. InitialIy this was provided by allocating to each team two senior designers each of whom was responsible for the control of two of the applications. Early in the life of the project it was not clear what form of software system would need to be developed for the project nor what form the central data-bank, to which all the applications would interface, would take. Two members of the design staff were allocated to considering respectively the software needs and the database needs of the project. Each senion designer, and each software expert, reported to the Chief Systems Designer. The structure of the team was then that of Fig. 2.

\section{DEVELOEMENTS OF THE TEAM STRUCTURE}

The team structure described in Section 3 was created to achieve two results, to eliminate the user-designer and designer-programer communication barriers which occur normally and to provide motivation. It proved satisfactory so long as the primary task was systems analysis on the broad outline of the systems design. Once detailed design work began then a number of holes began to appear. Among problems were:

1. Design staff tended to work in isolation, the provision of two senior designers per team merely aggravating the problem rather than easing it. This led to duplication of effort in many cases and problems of interfacing being "put off" and eventually 


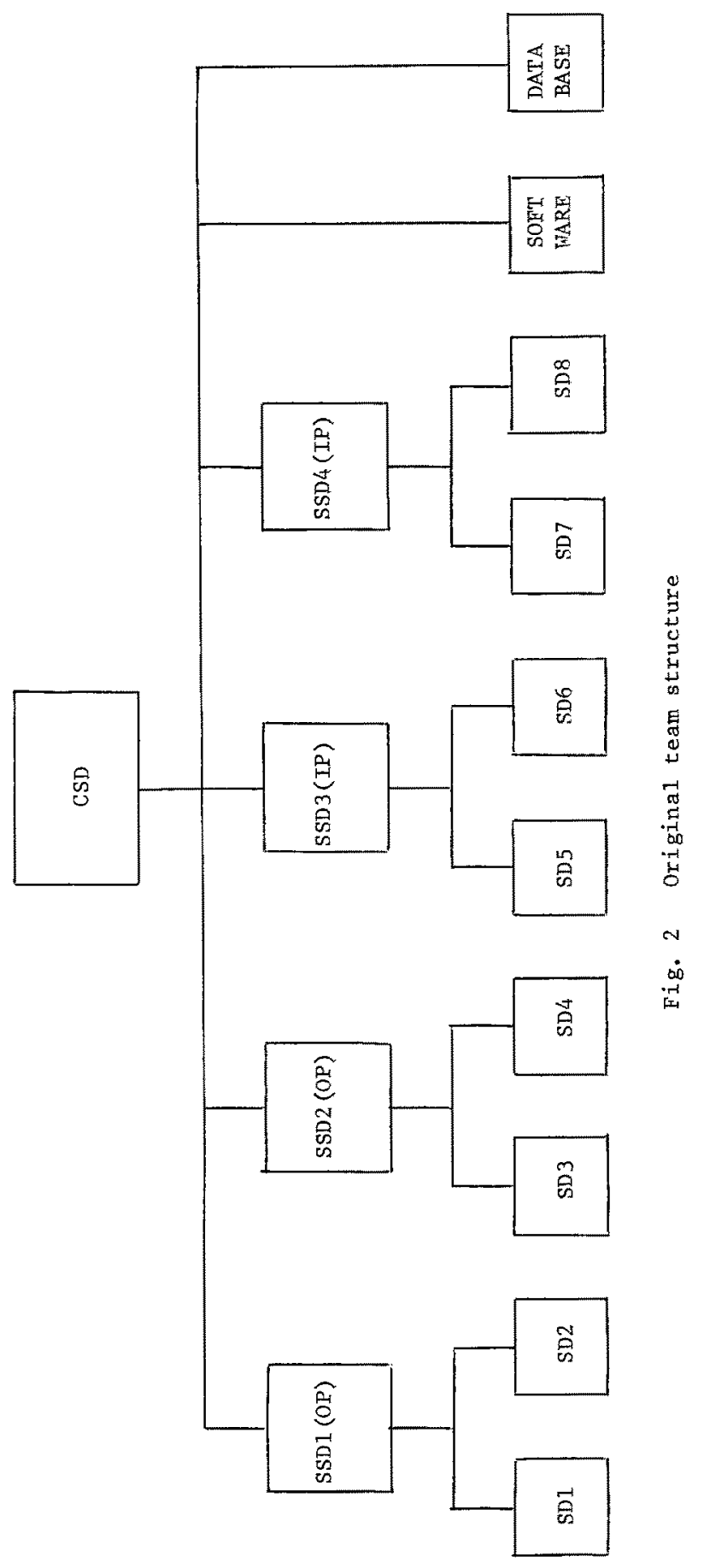


forgotten altogether, until they were rediscovered at the last minute.

2. Many areas of development clearly were the responsibility of no one designer. Such areas were not restricted to design work but covered also software and administrative tasks. Some examples were:

(a) Many transactions could be called from other transactions and had to store (and restore) information for the duration of the transaction. At the end they had to know where to neturn and what information to supply. The design and implementation of interfaces of this type was not the responsibility of any cne application.

(b) Each transaction needed to stone statistics about its performance to allow tuning to take place. It appeared to be the responsibility of nomone to design the form of storage or provide the programs to analyse the results.

(c) Aspects of systems design spread across many transactions, for example the provision of a stendard form for letters to patients covered outpatients (clinic appointments) and inpatients (admissions), and were the responsibility of more than one team.

(d) Physical alterations to the hospital environment needed to be effected before the computer systems could be implemented.

In practice the solution of each of these problems was undertaken by the first systems designer to meet it. This was not, however, satisfactory since in many cases problems were highlighted only after related pieces of design work had been completed. That design work then had to be repeated with corresponding loss of time.

3. The newly defined job of systems designen required a very wide spectrum of skills, varying from industrial psychologist to low level programmer (see section 5). In practice it was rane for a single individual to be able to cover the whole spectrum and some specialisation had to take place. This took the form of two individuals being allocated as advisors on software and central design matters and as writers of those machine code routines which were essential for the implementation of the applications.

In many IICS's it has proved necessary to undertake a major software exercise, finstly to provide a teminal handing package, secondly to provide a package to route the messages from the teminals to the appropriate applications programs and to return the replies, and thindly to provide a central filing system and file accessing method (see Fig. 1). Where this has happened there has been a need for a large software team structured in a similar way to the applications team described here. Where such a team has existed the problems referred to in $2(a)$ and $2(b)$ above have become the responsibility of the softwane team.

At Addenbrooke's, however, the situation was different. The equipment chosen for the project, a Xerox Sigma 6 computer, already had available transaction processing software (Xerox TP) and a database management system (EDMS) based on the CoDASYL proposals. 
Hence there was no need for a large team. Yet there was a need to interface to the suppliers, Rank Xerox Data Systems, and to provide general advice to the applications teams. The designer allocated to the study of software was suitable for the role of liaison-advising but was not sufficiently sentor to take over the design functions required by $2(a)$ and $2(b)$. Similarly there was a need for a database structure to be designed, again covering all applications and again requiring a designer with some degree of seniority. The responsibilities of the database designer would be those described in Palmer (1975).

The problems outlined at the beginning of this section were problems not of organisation but of communication. Nevertheless the organisation had to be one which supported, and not opposed, the communication mechanism.

The problems of gaps in the onganisation were covered in three ways:

1. By changing the role of the second senior designer in each team to that of an advisor on low-level programing and software.

2. By creating senior posts covering software design and implementation and database design and implementation.

3. By creating a post of administrator with responsibility for those areas of systems design which were concenned with the overall interface to the hospital at large, for example physical alterations and standard stationery.

The team structure now became that shown in Fig 3.

The problems of communication across applications could have been solved by the introduction of hierarchical managenent, already in being because of the need for project control. It was felt that this would reduce the motivation factor and would not be entirely effective. Instead a series of "think tank" sessions was introduced. Each team had its own session once per week. A combined session of senior designers with the chief systems designer was held every two weeks. Early in the project meetings of the whole project team were held regularly, at least once per month, but these were found to be more dismuptive than helpful, langely because different team members would interpret discussions in different ways and further meetings of the type described already would need to be held in order to resolve the differences. This system was backec up by an extensive standards manual covering eveny aspect of the project from administration to operations.

\section{STAFFING POLICY AND RECRUITMENT}

The skills required of any one systems designer in the organisation described above were extensive. They covered:

1. Operational Research - required both in the study of the uses to which the computer should be put and in the design of the on-line system itself (Martin, 1967).

2. Industrial Psychology - on-line systems introduced the idea of direct man-machine 


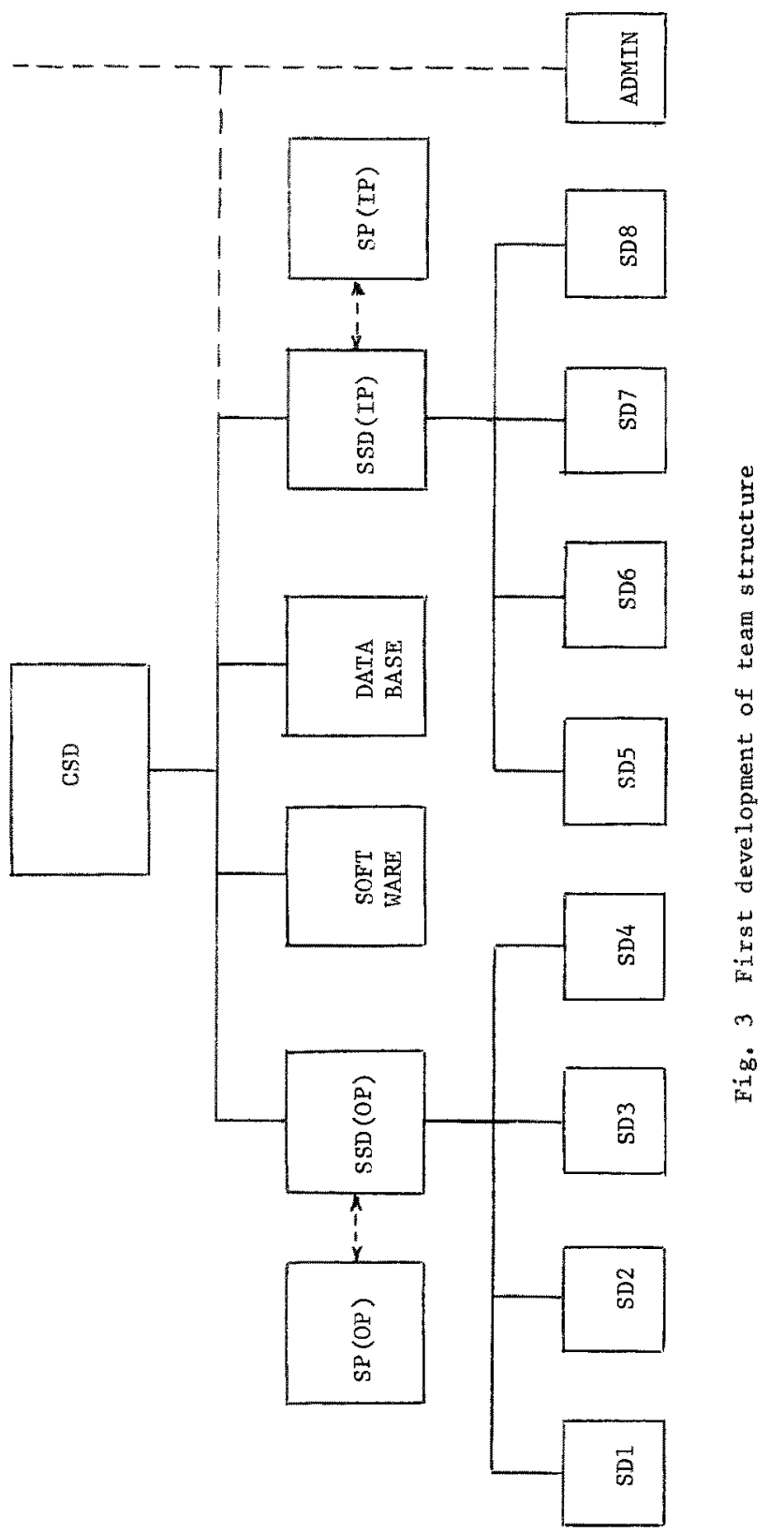


interaction (Martin, 1973). It was essnetial that the problems of the naive user in this respect (Eason, 1976) were understood if the implementation was to succeed.

3. Systems Analysis - the conventional systems analysis techniques were still needed. 4. Transaction Processing Software Design - the interactions between applications could be provided only in the context of facilities which were available in, or could be added to, the existing TP software.

5. Database Design - because of response time considerations the suitability of a particular implementation could be determined only in the context of how the database management system handled the data references. As many of the accesses were through chains and not direct this was highly significant.

6. Programing - all members of the team were required to program in COBOI and FORTRAN. Machine code programming was not essential but was encouraged. Later in the project the provision of an APL database interface required an extension of expertise.

7. Knowledge of Developments - the short implementation timescale required that the latest techniques of program development (where relevant) should be employed. The concepts of structured programing were introduced from the outset, on-line program development was introduced as soon as facilities became available.

Was it possible to engage staff to work on this basis?

Fortunately, the salaries which could be offered, the environment of the project within the hospital, and the nature of the computing activity were all aspects which made working with the team attractive. The problem was to ensure that recruitment strategies were directed towards those individuals whose pyschological needs for job satisfaction (Mumford, 1972) met most closely what the project had to offer. A number of different recruitment strategies were applied, for example:

1. To advertise specifying qualifications and experience in the broad sense, say a degree plus some on-line experience.

2. To advertise specifying only a restricted experience, say three years coBol programming.

3. To recruit directly from university, through official contacts and personal visits, and provide training.

4. To recruit from within the hospital service and provide training.

From the returns obtained by evaluating these strategies a clear profile emenged of the type of individual likely to be at home within the structure. He would be a graduate in either a scientific discipline or one with a logical content (e.g. music or philosophy). He would have had some computer training, either as part of his university course or subsequently, and he would have had some experience of the environment, in this case the hospital environment, either directly or through appropriate M.Sc courses. Alternatively it was found that computer professionals who had spent 
some time working with computer consultants on computen science students recruited directly from university were quick to adapt to the type of work. There were two groups who clearly did not fit the psychological role demanded by the organisation, hardware and software "boffins" and the large class of COBOL, PL/I, BAL, etc. programens who had developed within the conventional analyst/programmer environment.

In almost all cases a large amount of training had to be given, particularly in the fields of the role of the systems designer in a commercial organisation and in the nature of transaction processing and database design. In all planning it was assumed that training would take up the first six months of the time of any new member of staff. A feature of motivation is continuous careen development. To this end a large and comprehensive library was provided and staff were encouraged to read and to discuss the relevance of what they had read to the aims and conduct of the project. It was important that staff should not be allowed to drift into the domain of ignorance discovered by Parkin (1975). In addition, to emphasize their involvement in their own career progress they were encouraged to publish any results which they derived which were not affected by considerations of medical confidentiality. This policy was deliberate and in direct contradiction to that employed in conventional DP installations (Fisher, 1974). A full knowledge of what had gone before and an insight into the theoretical background of what they were doing was considered essential if systems designers were to plan thein work according to known and successful concepts. 6. THE ROIE OF THE CHIEF PROGRAMMER

In the structure defined above there appears to be no one who has the direct responsibility for defining programing standards, defining prognaming timetables, and monitoring that both the standards and the timetables were being kept. In the conventional installation this would be the role of the chief programer.

Where the development of an IICS has included a large software exercise the role of the chief programmer has become that of a chief software designer, with responsibility for application program standards and timetables passing to the senior programmers in the application teams. At Addenbrooke's there was no major software exercise and hence no need for a chief software designer. In practice the planning of timescales and the monitoring of progress and standards was taken up naturally by the senior designers in each team. The outstanding task was the establishment of standards. Many of these were defined through the manufacturer supplied software and needed only to be communicated. The project standards documentation system referred to earlier was adequate to cope with this. The remainder were concerned with problems which arose within teams but applied across teams. Here a definitive solution was required. This problem alone did not justify the appointment of a chief programmer and was solved by further sub-team meetings, this time between the senior programmers and senior software and database designers and the chief systems designer, taking place monthly. 
An obvious conclusion is that in a team developing an IICS there is no role for a chief programer. Not only is this the case but the creation of such a post is likely to create problems because of the significant overlap of duties between the chief programmer and the chief systems designer. It has been noted that in those organisations developing IICS's, where a chief programmer has been appointed and his changed role has not been clearly defined, then this has led to a noticeable strain.

\section{THE CHIEF PROGRAMMER TEAM CONCEPT}

One obvious problem of the application orientated structure was that individual computer staffs did not work at the same rate, nor did each group of applications involve the same amount of work. Although applications could not be implemented at the same time the rate of individual progress was not known before work began on an application and the affect of unforseen problems on different applications could not be predicted. This problem of differing rates of progress had led, in a different context, to the formation of the Chief Programner Team concept (Baker,1972). It is interesting to note how a similar concept developed at the Addenbrooke's project. Addenbrooke's had an additional problem. Staffing levels were fixed and loss of production caused by staff leaving could be made up only by employing progranmers on a fixed term basis. If one application slipped badly it was likely that another, later in the implementation schedule, would be ahead. The designer who was ahead could move over to assist the designer attempting to catch up and could most meadily assist by taking over the testing and training function. The freelance programmer also could be assigned to assist with the application and was usually found to be most useful in the area of programing incidental background jobs, for example the printing of back-up versions of directories overnight. The administrator already was responsible for the general aspects of documentation and hospital interfacing. Hence a team consisting of chief programmer, back-up programmer, librarian, and secretary had been formed by accident. From this result it seems likely that the optimum onganisation for the development of a large IICS is a set of chief programmer teams each allocated to an application. Support for such a conclusion was given by the team implementing the LACES project.

\section{THE PROGRAMMER-OPERATOR RELATIONSHIP}

In batch processing installations the relationship between operators and programmers usually is one of segregation. The computer room is the shrine of the operators into which the programmer must not stray. An operator may not comment ori a program, he may only run it on demand, according to the instructions supplied, and return the output promptly.

In on-line installations such an arrangement is not practicable. Whilst systems are under test, or when a software fault arises during live running, programmers must have access to the computer. If a fault occurs then operators must be involved. They are first in the firing line for the wrath of the users and they are the first level 
for attempting to effect a recovery. A further problem is that when the on-line service is live, and invariably taking over the whole of the computer, there is little for the operators to do.

One solution is to have two computers. At Addenbrooke's this solution is not possible due to insufficient total load on the computer. Hence there is a need for an alternative. The on-line netwonk is live from 0800 to 1800 and during this time no system testing other than the final parallel run can proceed. In the evening there is a competing demand for resources from the operators running the background batch work and the programmers wishing to do systems testing.

At the time of writing the problem has been identified but no firm solution reached. Clearly, however, any solution must involve some form of overlap between the duties of operators and programmers. It will be interesting to see the affect of any solution on the team structure defined above. Previously operations had employed a hierarchical management structure, reporting to the project director and independent of that designed for the applications teams.

\section{CONCLUSIONS}

When the Addenbrooke's IICS project was established a positive attempt was made to create a team structure through which the problems of communication would be removed and motivation increased, leading to higher productivity.

A measure of the success of communication is the extent to which the system created meets the real needs of the user and does not prove ineffective due to poon systems design. Against this measure it is possible to claim a fair degree of success. The principal users are enthusiastic, there have been no complaints of misinterpretation and only one case has come to light where the techniques for man-machine interfacing have fallen short.

Measures of the degree of productivity achieved are the speed at which "fully tested" systerns are produced and the number of errons found in the final product. The actual rate of production achieved for the first group of applications was 35,000 lines of code (mixed COBOL, FORTRAN, and machine code) from eight man years of effort, including all systems analysis and design. It was not possible, however, to relate this to any other achievement for two reasons. Firstly the project was subjected to many delays from outside over which it had no control. Secondly, the use of high level languages, the use of structured programing techniques, and the availability of online program development facilities all contributed to improving productivity. The part played by any one of these factors could not be identified. To date sixty three errors have been found in the initial applications. None of these has been sufficientIy serious to require the on-line system to be withdrawn while repair was effected, even for seconds. Measured against these criteria of productivity it is believed that the performance of the team rates quite high. 
One major defect of the application orientated structure is clear. It is very vulnerable to staff leaving and it makes it difficult for staff to move between applications. It encourages staff to become inward looking and to be resistant to criticism from others. On the other hand the stmucture does generate motivation and job satisfaction. The average length of stay within the project is over three and a half years, which again compares favourably with similar installations.

10. REFERENCES

BAKER, F.T. (1972). Chief programer team management of production programming. IBM Systems Journal, Vol. 11, No. 1, pp. 56-73.

COATES, H.N. (1974). Management in the computer business. The Computer Joumal, Vol. 17, No. 3, pp. 279-282.

EASON, K.D. (1976). Understanding the naive computer user. The Computer Journal, Vol. 19, No. 1, PP. 3-7.

FISHER, G.A. (1974). Letter to the editor. The Computer Journal, Vol, 17, No. I, p. 95 .

HAMMERSELY, P. (1972). Principles of control in patient administration. Proceedings of the Toulouse Conference 'Journees d'Informatique Medicale', IRIA, Vol. 1, DP 3I9335 .

HARDCASTLE, A.R.K. (1971). Management implications of DP systems. The Computer Bulletin, Vol. 15, No. 2, pp. 60-62.

MARTIN, J. (1967). Design of real-time computer systems, Prentice-Hall.

MARTIN, J. (1973). Design of man-computer dialogues, Preñtice-Hall.

MUMFORD, E. (1972). Job satisfaction, Longman.

PALMER, I. (1973). Database management, SCICON.

PARKIN, A. (1975). Professional programners - do they read? Computer Bulletin, Series 2, No. 4, P. 13. 